\title{
Inefficient Group Organization as Optimal Adaption to Dominant Environments
}

\author{
Martin Kolmar \\ Andreas Wagener
}

CESIFO WORKING PAPER NO. 3157

CAtegory 2: Public CHOICE

August 2010
An electronic version of the paper may be downloaded
- from the SSRN website:
- from the RePEc website:
- from the CESifo website:
www.SSRN.com
Www.RePEc.org
www.CESifo-group.org/wp




\title{
Inefficient Group Organization as Optimal Adaption to Dominant Environments
}

\begin{abstract}
Contests between groups are plagued by intra-group externalities (freeriding). Yet, costless incentive schemes that entirely avoid free-riding within a group might not be desirable, neither individually nor socially. In contests among two groups, a relatively weak (i.e., small or unproductive) group will optimally not implement them because they compound strength differences between groups. If both groups rein in their intra-group externalities, they are both worse off, compared to a situation with free-riding, if they are relatively similar. If they are sufficiently heterogenous, the weak group loses at the expense of the relatively strong group.
\end{abstract}

JEL-Code: Z13, D72, N40, D74.

Keywords: conflict, incentives, group-size paradox.

\author{
Martin Kolmar \\ Institute for Empirical Economics and \\ Economic Policy \\ University of St. Gallen \\ Varnbüelstrasse 14 \\ CH - 9000 St. Gallen \\ Switzerland \\ martin.kolmar@unisg.ch
}

\author{
Andreas Wagener \\ University of Hannover \\ Department of Economics and Management \\ Koenigsworther Platz 1 \\ 30167 Hannover \\ Germany \\ wagener@sopo.uni-hannover.de
}

July 26, 2010 


\section{Introduction}

"There are only 2 qualities in the world: efficiency and inefficiency, and only 2 sorts of people: the efficient and the inefficient."

George Bernard Shaw

"The average man has a carefully cultivated ignorance [...] - a sort of cheerful inefficiency which protects him."

Crystal Eastman

If groups rather than individuals compete against each other in a contest, a freerider problem among members of each group arises: when contributing to its group's effort in the contest, every individual bears the full marginal costs while the marginal benefits partly spill over to the rest of the group (e.g., Konrad 2009, Chs. 5.5 and 7). The attending positive externalities arise both if the contested rent is a groupspecific public good (Katz, Nitzan, and Rosenberg 1990, Esteban and Rey 2001, Epstein and Mealem 2009, Nitzan and Ueda 2009) or if the rent is a private good (Nitzan 1991a,b; Esteban and Rey 2001, Nitzan and Ueda 2009).

The intensity of free-riding or, conversely, the motivation of individuals to exert effort is determined by the intra-group incentive scheme. In standard contest games, these incentives are unseparably linked to the sharing rule, i.e. to the (usually exogenous) procedure by which acquired rents are distributed within the group. ${ }^{1}$ In a number of economic applications, however, incentives to exert effort appear to be separate from the sharing rule. Think, e.g., of phenomena such as team spirit, identification with the group, or norms to contribute to the social good. In such scenarios, individual members behave co-operatively (i.e., in the interest of the entire group) - even if the distribution of rents follows a standard sharing rule. Alternatively, the group could apply an incentive scheme that marginally equates individual and group incentives. Such schemes were discussed by Nitzan and Ueda (2009) as a means to motivate group members. We call an incentive scheme that aligns individual behaviour with group interest an intra-group efficient incentive scheme (IGEIS).

Nitzan and Ueda (2009) study a contest where all competing groups jointly, but exogenously implement an (costless) IGEIS. They show that larger groups beenfit from such schemes at the expense of smaller ones. They do not, however, allow

\footnotetext{
${ }^{1}$ See, e.g., Nitzan (1991a,b), Baik and Lee (2001), Noh (2002) or Bloch et al. (2006).
} 
for the possibility that groups voluntarily and unilaterally implement an IGEIS. More technically, they do not determine the Nash equilibrium for the adoption of incentive schemes. At first glance, this restriction seems innocuous. Why would a group that has free access to an IGEIS not utilize it? After all, an IGEIS internalizes all within-group externalities. We show that this intuition does not hold for contests. If the competing groups have sufficiently unequal strengths (due to unequal sizes or different comparative advantages), the weaker group may wish not to implement an IGEIS even if that was costless. The rationale is to avoid the contest from heating up: if group $A$ is relatively weak, group $B$ 's effort is a strategic complement to group $A$ 's effort, whereas group $A$ 's effort is a strategic substitute to group $B$ 's effort. Thus, if an IGEIS makes group $A$ more efficient (and, thus, more aggressive) in the contest, group $B$ will show more aggression too. This compounds differences in contest strengths and the share of the rent that the weaker group can acquire shrinks. This effect may outweigh the benefits from a better intra-group organization.

This observation has an analogy in rent seeking contests with an endogenous order of moves (Baik and Shogren 1992, Leininger 1993, Nitzan 1994). These papers show that in a two-player Tullock contest where both players can choose the levels as well as the timing of effort, the weaker player, or - using the terminology of Dixit (1987) - the "underdog" always moves first. From the underdog's point of view, the favorite's effort is a strategic complement to its own effort, whereas the opposite is true from the point of view of the favorite. This strategic complementarity can be used to reduce effort if the underdog moves first. A similar mechanism is at work here: If a group is sufficiently weak, an increase in its efforts would be disproportionately retaliated by the other, stronger group. Sticking with inefficient group incentives helps to keep the contest temperate.

In group contests, a greater efficiency within groups may also be undesirable from the perspective of social welfare: it makes groups more aggressive, the costs of the contests increase, rent dissipation rises, and social welfare is reduced.

This finding adds a new element to the discussion about the group-size paradox (Olson 1965, Esteban und Rey 2001, Pecorino and Temimi 2008, Nitzan and Ueda 2009). This paradox posits that group size and effectiveness in collective action are inversely related for the case of collectively provided private goods, but positively associated when non-rival goods are collectively provided. Esteban and Rey (2001) have shown that this - in their terms - "general wisdom" need not be correct 
if the costs of effort are sufficiently convex. ${ }^{2}$ Our result pushes this finding one step further: Independently of the nature of the rent earned from collective action, (relatively) larger group have a stronger incentive than smaller ones to increase their effectiveness in collective action (by introducing an IGEIS). Relatively small groups cannot only afford it more easily to remain inefficient (as their free-rider problem is less severe), any attempt of this group to solve its internal organization problem will be retaliated by the other group, diluting the potential benefits of efficient within-group incentives. The inefficient organization of a relatively small/weak group may therefore be simply an expression of its relative smallness and/or weakness, an optimal adoption to its dominant environment. Hence, relatively large groups may end up with a comparative advantage for collective action precisely because of their large free-rider problems, and seemingly inefficient organizational structures for collective action in smaller groups may be deliberately chosen to limit the adverse consequences of one's weakness.

Section 2 introduces a model that captures these effects. Section 3 analyzes the attending game before Section 4 discusses welfare implications. Section 5 concludes.

\section{$2 \quad$ A model of group incentives}

We model a contest between two groups, $A$ and $D$. Group $k=A, D$ consists of $N_{k} \geq 2$ identical members. Without loss of generality, we set $N_{D}=N$ and write $N_{A}=\alpha N_{D}=\alpha N$ for some $\alpha \geq 2 / N_{D} \cdot{ }^{3}$ The two groups compete against each other for a given rent. As in Esteban and Rey (2001), this rent has a rival component, $R$, as well as a public component, $P .{ }^{4}$ Using $z \in[0,1]$ to measure the degree of publicness of the rent and assuming that an equal-sharing rule is applied to distribute the rival part of the rent within a group, a generic member of group $D$ [of group $A]$ has a

\footnotetext{
${ }^{2}$ Pecorino and Temini (2008) at least partly re-established the "general wisdom" by allowing for small fixed costs. In the same spirit, Nitzan and Ueda (2009) explicitly model the withingroup utilization of the good and show that this generalization strenghtens the possibility of the group-size paradox.

${ }^{3}$ At some places in this paper, we treat $\alpha$ as if it could vary continuously. This is for expositional simplicity only; restrictions on $\alpha$ to ensure that $N_{A}$ is an integer would not affect any of our observations.
}

${ }^{4}$ See also Nitzan (1991a, b) who has first analyzed group contests for private and public goods. 
benefit of

$$
(1-z) \frac{R}{N}+z P \quad\left[\text { respectively, of }(1-z) \frac{R}{\alpha N}+z P\right]
$$

in case his group wins the rent.

The members of groups $A$ and $D$ voluntarily invest efforts $a=\left\{a_{1}, \ldots, a_{N_{A}}\right\}$ and $d=\left\{d_{1}, \ldots, d_{N_{D}}\right\}$ in the contest. The probability $p_{k}$ that the contest is won by group $k=A, D$ is determined by a generalized Tullock contest-success function ${ }^{5}$

$$
p_{A}(a, d)=\frac{\theta \cdot \sum_{i=1}^{\alpha N} a_{i}}{\theta \cdot \sum_{i=1}^{\alpha N} a_{i}+\sum_{i=1}^{N} d_{i}} \quad \text { and } \quad p_{D}(a, d)=\frac{\sum_{i=1}^{N} d_{i}}{\theta \cdot \sum_{i=1}^{\alpha N} a_{i}+\sum_{i=1}^{N} d_{i}} .
$$

The parameter $\theta>0$ measures the relative effectiveness of group $A$; if $\theta>1$ group $A$ is c.p. more efficient than group $B$. Hence, we allow for two sources of asymmetry between the groups, relative group size $\alpha$ and an innate comparative (dis-)advantage $\theta$. Individuals are risk neutral, and the opportunity costs of investments and the rent are perfect substitutes.

We analyze two different incentive schemes, one with non-internalized intra-group externalities and an intra-group efficient incentive scheme (IGEIS). With the former, group members choose their effort levels in view of individuals benefits, as given in (1). This coincides with the standard approach to contests. If an IGEIS is applied, every group member behaves as if she maximized aggregate group welfare, viewing the value of the rent as $(1-z) R+z N_{k} P$. This is tantamount to assuming that individuals act as if maximizing a utilitarian welfare maximization which, given our assumptions on the utility functions, is equivalent to aiming at Pareto efficiency. An IGEIS is merely an incentive device, which does not alter the total quantity of resources or their actual distribution: if a group wins the contest, the rent is still shared equally and every group member "only" consumes $(1-z) R / N_{k}+z P$.

In standard contests (i.e., without an IGEIS), individual efforts involve a positive externality: they increase the group's probability to win the rent, a benefit that spills over to all group members. ${ }^{6}$ With an IGEIS, individual and social (marginal) benefits

\footnotetext{
${ }^{5}$ For expositional simplicity we suppress parameters $\theta, \alpha$, and $N$ as arguments of functions when not needed.

${ }^{6} \mathrm{~A}$ small increase in effort by a member of group $k$ increases the winning probablity for that group by $\mathrm{d} p_{k}$. Excluding effort costs, this increases group welfare by $\left[(1-z) R+z N_{k} P\right] \cdot \mathrm{d} p_{k}$ and individual utility by $\left[(1-z) R / N_{k}+z P\right] \cdot \mathrm{d} p_{k}$. The difference between these values is positive. Hence, a positive marginal externality.
} 
from effort choice are equated; individuals behave as if intra-group externalities were internalized. To illustrate, an IGEIS could be a Clark-Groves-Vickrey type of incentive scheme or result from individuals adopting a team spirit or a group identity in the sense of Akerlof and Kranton (2003).

We assume that a perfect and costless IGEIS is available. We do, of course, not claim that this is the case in reality. Yet, the assumption of a costless IGEIS makes our point as strong as possible - as we plan to derive conditions under which a group will voluntary abstain from using such a seemingly ideal tool.

We code the adoption of an IGEIS by group $k$ by $s_{k}=1$ and non-adoption by $s_{k}=0$. Formally, the two cases differ by what group members perceive as the behaviourally relevant rent (per group member) from the contest. Denoting these rents for groups $A$ and $D$ by, respectively, $W_{A}\left(s_{A}\right)$ and $W_{D}\left(s_{D}\right)$, we obtain:

$$
W_{A}\left(s_{A}\right)= \begin{cases}(1-z) R+z \alpha N P & \text { if } s_{A}=1 \\ (1-z) R /(\alpha N)+z P & \text { if } s_{A}=0\end{cases}
$$

and

$$
W_{D}\left(s_{D}\right)=\left\{\begin{array}{l}
(1-z) R+z N P \text { if } s_{D}=1 \\
(1-z) R / N+z P \text { if } s_{D}=0
\end{array}\right.
$$

(see Esteban and Rey 2001). Observe that $W_{k}(0)$ coincides with the actual rent (1), while $W_{k}(1)=N_{k} W_{k}(0)$ equals the total rent for the entire group.

We study a two-stage game where groups first and simultaneously decide whether to use the IGEIS or not and then, given these choices, play a simultaneous contest game at the second stage. The game is solved by backwards induction.

\section{The game}

\subsection{The contest at stage 2}

We determine the Nash equilibria of the contest subgame for all combinations of $\left(s_{A}, s_{D}\right)$, i.e., for $(0,0),(1,0),(0,1)$, and $(1,1)$. Members of groups $A$ and $D$ behave as if they maximized utility functions

$$
u_{k}^{i}(a, d)=p_{A}(a, d) \cdot W_{A}-a_{i} \quad \text { and } \quad u_{D}^{i}(a, d)=p_{D}(a, d) \cdot W_{D}-d_{i},
$$


depending on $\left(s_{A}, s_{D}\right)$ as specified above. Restricting attention to symmetric equilibria where all members of the same group make equal investments, ${ }^{7}$ we obtain effort levels as

$$
\begin{aligned}
& a_{i}^{*}\left(s_{A}, s_{D}\right)=\frac{W_{A}\left(s_{A}\right)}{\alpha N} \cdot \frac{\theta W_{A}\left(s_{A}\right) W_{D}\left(s_{D}\right)}{\left(W_{D}\left(s_{D}\right)+\theta W_{A}\left(s_{A}\right)\right)^{2}}, \\
& d_{i}^{*}\left(s_{A}, s_{D}\right)=\frac{W_{D}\left(s_{A}\right)}{N} \cdot \frac{\theta W_{A}\left(s_{A}\right) W_{D}\left(s_{D}\right)}{\left(W_{D}\left(s_{D}\right)+\theta W_{A}\left(s_{A}\right)\right)^{2}} .
\end{aligned}
$$

Since $W_{k}(1)>W_{k}(0)$ we obtain that, given the other group's choice of $s$, an individual exerts greater efforts in the contest when his group has adopted an IGEIS: $a_{i}^{*}\left(1, s_{D}\right)>a_{i}^{*}\left(0, s_{D}\right)$ and $d_{i}^{*}\left(s_{A}, 1\right)>d_{i}^{*}\left(s_{A}, 0\right)$. This simply reflects the IGEIS' potential to rein in within-group externalities.

We denote the associated utility levels of the contest subgame by $V_{A}\left(s_{A}, s_{D}\right)$ and $V_{D}\left(s_{A}, s_{D}\right)$, respectively. These values are calculated using actual benefits, i.e., using in (3) the rents from (1) rather than $W_{k}$ (for $s_{k}=1$ ).

\subsection{The choice of an incentive scheme at stage 1}

We assume that an IGEIS is implemented by a group if it increases the per-capita (indirect) utility of its group members, i.e., if $V_{A}\left(1, s_{D}\right)>V_{A}\left(0, s_{D}\right), V_{D}\left(s_{A}, 1\right)>$ $V_{D}\left(s_{A}, 0\right)$. Obviously, in a non-strategic environment it is always optimal to implement an IGEIS: it internalizes the otherwise persistent intra-group externalities. For a contest environment the case is less obvious. The adoption of an IGEIS by, say, group $A$ not only influences the behavior of the members of this group, but has spillover effects on the behavior of group $D$. This repercussion is helpful from the point of view of group $D$ if a more aggressive behavior of group $A$ makes group $D$ less aggressive. In the opposite case, however, the net effect is not clear. The optimal decision for or against an IGEIS depends on whether group A's and group $D$ 's investments are strategic substitutes or complements as well as on the absolute strength of the effect (because the choice problem is discrete). The following proposition characterizes the equilibrium choice of incentive schemes.

Proposition: There exist threshold values $\underline{\theta}(\alpha)$ and $\bar{\theta}(\alpha)$ with $0<$ $\underline{\theta}(\alpha)<\bar{\theta}(\alpha)$ such that:

\footnotetext{
${ }^{7}$ Baik (2008) has shown that the effort (sub-)game has multiple equilibria. All equilibria share, however, that the sum (within each group) of efforts is identical, which implies that our restriction on symetric equilibria has no influence on the aggregate winning probabilities of the two groups.
} 
1. If $\theta<\underline{\theta}(\alpha)$ the Nash equilibrium is $s_{A}=0, s_{D}=1$.

2. If $\underline{\theta}(\alpha)<\theta<\bar{\theta}(\alpha)$ the Nash equilibrium is $s_{A}=s_{D}=1$.

3. If $\theta>\bar{\theta}(\alpha)$ the Nash equilibrium is $s_{A}=1, s_{D}=0$.

4. If $\theta=\underline{\theta}(\alpha)$, there are two Nash equilibria: $s_{A}=0, s_{D}=1$ and $s_{A}=$ $s_{D}=1$. If $\theta=\bar{\theta}(\alpha)$, there are two Nash equilibria: $s_{A}=1, s_{D}=0$ and $s_{A}=s_{D}=1$.

Figure 1 gives a graphical representation of Proposition $1 .^{8}$ The figure reveals that

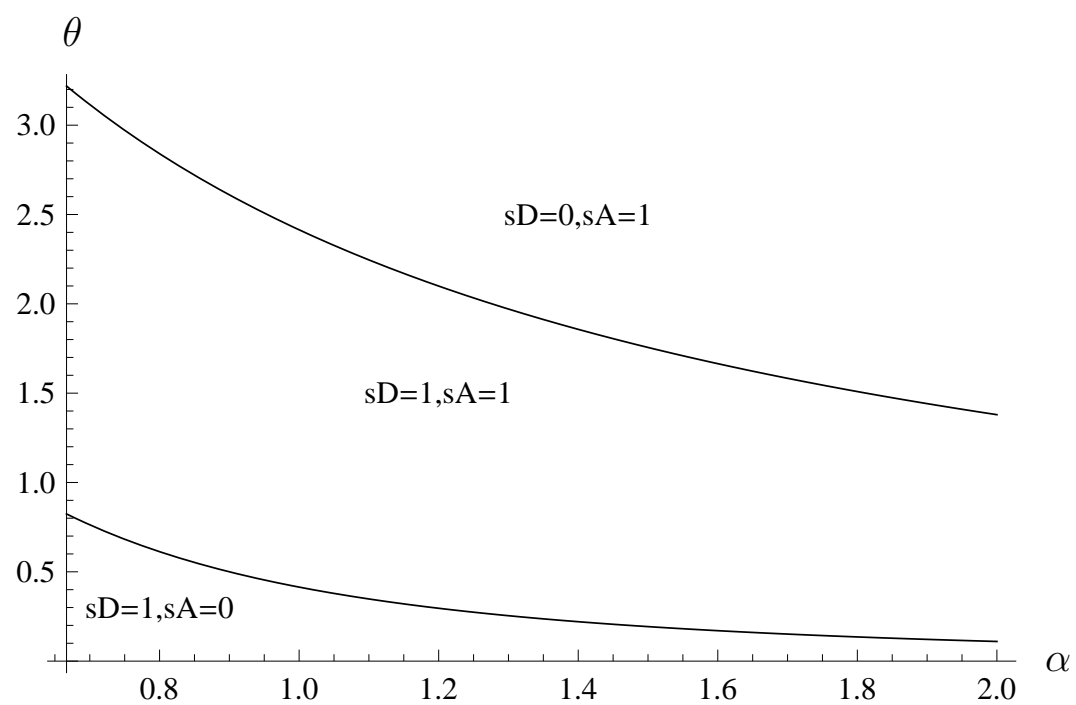

Figure 1: Equilibria for different $\alpha-\theta$-combinations $(N=3, R=1, P=1, z=0.5)$.

relatively "weak" groups may abstain from introducing an IGEIS, where from the point of view of group $A$ (the opposite is true for group $D$ ) weakness refers to a combination of low $\theta$ and low $\alpha$. It is clear that group $A$ is favored by large values of $\theta$, however, in the light of the group-size paradox (Olson 1965, Esteban and Rey 2001 ) it is not clear that large values of $\alpha$ favor group $A$. A relatively large group size only creates the potential for strength that can only be exploited if the within-group incentive problem is solved. In that case, however, potential is transformed into actual strength. As a consequence, asymmetric equilibria are possible if differences in relative size and/or contest productivity are large.

\footnotetext{
${ }^{8}$ In Appendix A.1, we derive that $\underline{\theta}(\alpha)=0.5 \Phi(\alpha)(\sqrt{(\alpha N-2) \alpha N+5}-(\alpha N-1)), \bar{\theta}(\alpha)=$ $0.5 \Phi(\alpha)(\sqrt{(N-2) N+5}+(N-1))$, and $\Phi(\alpha)=\frac{(1-z) R+z N P}{(1-z) R+z \alpha N P}$. These are all decreasing functions of $\alpha$, and it is straightforward to check that $\bar{\theta}(\alpha)>\Phi(\alpha)>\underline{\theta}(\alpha)$ for all $\alpha$.
} 
To get a better intuition for this result it is useful to extend the concepts of "favorite" and "underdog" from Dixit (1987) to group contests. Group $A$ is called the underdog [the favorite] if the cross-partial derivative of the contest success function, evaluated at the Nash equilibrium of the contest subgame,

$$
p_{A}^{a d}:=\frac{\partial^{2} p_{A}\left(a^{*}, d^{*}\right)}{\partial a_{i} \partial d_{j}}
$$

(for generic group members $i, j$ ) is negative [positive]. Since $p_{D}^{d a}=-p_{A}^{a d}$ by construction, group $D$ is a favorite [underdog] whenever group $A$ is an underdog [favorite]. If group $A$ is a favorite, then its effort in the contest is a strategic complement to the underdog $D$ 's effort and, conversely, the underdog $D$ 's effort is a strategic substitute to group $A$ 's effort (and mutatis mutandis when $A$ is the underdog). Favorites become more aggressive when the contestant increases its contest effort. Underdogs, however, duck out.

In the Appendix we show that, if an asymmetric equilibrium emerges, the group that implements an IGEIS (i.e., the relatively large or effective group) must be a favorite while the other group is an underdog. An increase in the effort of the favorite would reduce effort by the other group (whose investment is a strategic substitute to the favorite's investment), whereas an increase in the underdog's would encourage the other group to also increase effort (the favorite's investment being a strategic complement to the underdog's investment by $j$ ). In the intermediate cases (where a symmetric equilibrium occurs), the cross effects are relatively weak.

This finding adds an interesting new aspect to the discussion about the validity of the group-size paradox: relatively large groups may end up with a comparative advantage exactly because their large free-rider problem puts pressure on the establishment of efficient incentive schemes.

The second important aspect of this finding is that an apparently inefficient internal organizational structure may be optimal after all: it is rationally selected by underdogs to keep the contest more temperate. As a general lesson, incentive schemes can only be assessed properly in knowledge on the economic environment in which the organization exist that choose them. 


\section{Welfare}

The strategic interdependence of the groups' organizational choices may lead to a social dilemma: even if it is optimal for both groups to introduce an IGEIS, the consequence may be that both groups are worse-off in equilibrium. Analogously, it is possible in an asymmetric equilibrium that a group that introduces an IGEIS profits at the expense of the other group. To analyze this question, we compare the utility levels in equilibria with and without IGEIS.

We start with the case of equally-sized groups:

Proposition 2: Assume that $\alpha=1$. Compared to a situation $s_{D}=$ $s_{A}=0$,

1. group $D$ is better off and group $A$ is worse off if $\theta<\underline{\theta}$;

2. both groups are worse off if $\underline{\theta} \leq \theta \leq \bar{\theta}$; and

3. group $A$ is better off and group $D$ is worse off if $\bar{\theta}<\theta$.

This finding reveals two properties of the "incentive game". First, if neither group has a sufficiently large comparative advantage in the contest, the choice of an IGEIS has a typical prisoners' dilemma structure (item 2). Second, if one of the groups has a sufficiently large comparative disadvantage in the contest that an asymmetric equilibrium results, this group profits at the expense of the other group by the introduction of an IGEIS (items 1 and 3).

For groups of unequal sizes the following results can be established:

Proposition 3a: Assume that $\underline{\theta} \leq \theta \leq \bar{\theta}$ (i.e., both groups choose an IGEIS). Compared to a situation where both groups have a simple sharing rule,

1. both groups are worse off if they have similar sizes;

2. group $A$ is better off [worse off] if its group size $\alpha N$ is sufficiently larger [smaller] than the group size of $D, N$.

The opposite result to 2 . holds for group $D$. 
Part 1 of Proposition 3a follows the same logic as Proposition 2. The introduction of an IGEIS makes both groups more aggressive. If both groups are relatively similar, the resulting effect on the equilibrium probability is relatively small such that the effect on welfare is negative. For unequal group sizes, part 2 shows that a large group can be better off in an equilibrium with IGEIS. Following the above line of argumentation, the effect on equilibrium probabilities is sufficiently biased in favor of the larger group in this case. This guarantees for this group an increase in group welfare.

We now show that this intuition carries over to the case of asymmetric equilibria:

Proposition 3b: Assume that $\theta<\underline{\theta}[\theta>\bar{\theta}]$. Group $D[A]$ benefits at the expense of group $A[D]$ compared to a situation where both groups apply a simple sharing rule.

Figure 2 summarizes our findings. The figure is a identical to Figure 1 with the

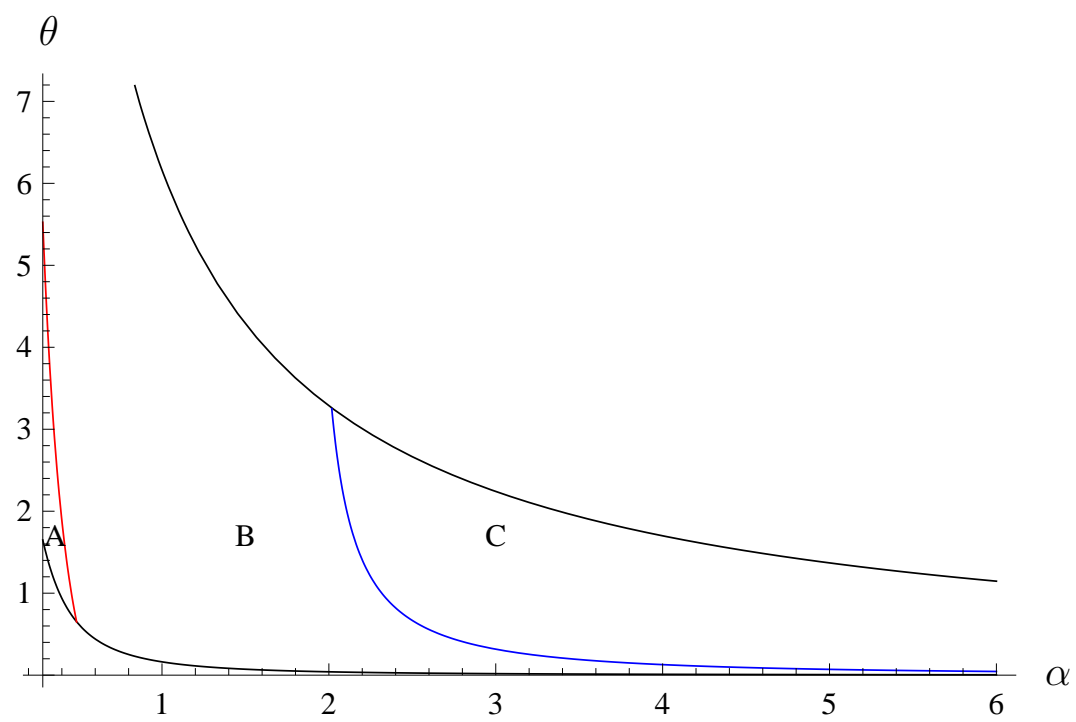

Figure 2: Welfare effects for different $\alpha$ - $\theta$-combinations $(N=7, R=1, P=1$, $z=0.5)$.

exception that we divide the range of $(\alpha, \theta)$-combinations that lead to an equilibrium where both groups choose an IGEIS is further divided into three subregions. Both groups are wore-off compared to the equilibrium with an equal-sharing rule in area $B$. Group $D$ profits at the expense of group $A$ in area $A$ as well as at all points 
below the lower black graph $\underline{\theta}(\alpha)$. Group $A$ profits at the expense of group $D$ in area $C$ as well as at all points above the upper black graph $\bar{\theta}(\alpha)$.

\section{Conclusions}

Incentive schemes are of crucial importance for the behavior of individuals in group contests. They help to rein in free-riding among group members and thus ceteris paribus help to increase the share of the rent that can be appropriated in the contest. Yet, this does not imply that the internalization of intra-group externalities is a dominant strategy or even welfare-improving. If a group is relatively weak, it may fare better when leaving its members with only weak incentives to expend (fruitless) effort in a contest with a stronger rival. Moreover, the additional aggression induced by high-powered incentives may be socially wasteful (increase in rent dissipation).

Our findings shed new light on the persistence of apparently inefficient organizational structures. Incentive schemes applied within organizations can in general not be evaluated without taking into account the competitive environment of the organization. What appears to be inefficient from an isolated, single-group perspective may be an optimal adaptation to a specific contest environment.

In addition our results in a sense turns the group-size paradox upside down. Esteban and Rey (2001) have shown that larger groups need not be less effective than smaller groups. On the contrary, if the costs of effort are sufficiently convex, larger groups may end up in a better position. Our paper shows that even in a situation with constant marginal costs, larger groups may end up in a better position because they have a more urgent need to introduce efficient incentive schemes. Of course this result recommits the discussion to a meta level: the implementation of an efficient incentive scheme has the character of a group-specific public good. If it comes along with some fixed costs of implementation (from which we abstract), it may create a group-size problem of its own. 


\section{Appendix A: Proofs for Section 3}

\section{A.1: Proof of Proposition 1}

Group D: (i.) Suppose group $A$ chooses $s_{A}=0$. Then for a member of group $D$, the utility differential between $s_{D}=1$ and $s_{D}=0, \Delta_{D}\left(1,0 \mid s_{A}=0\right)=$ $V_{D}(0,1, \theta, \alpha, N)-V_{D}(0,0, \theta, \alpha, N)$ is larger than zero if and only if

$$
\begin{aligned}
& \frac{\alpha N^{3}((1-z) R+z N P)}{(1-z) R \theta+\alpha N((1-z) R+P(N+\theta) z))^{2}} \\
& -\frac{(N-1) R \theta(1-z)+\alpha N((1-z) R+z P(N+(N-1) \theta))}{(R(\alpha+(1-z) \theta)+\alpha(N z P(1+\theta)-R))^{2}}>0 .
\end{aligned}
$$

This is non-negative iff

$$
\theta \leq \theta_{D}^{1}:=\frac{\alpha N}{2} \Phi(\sqrt{N(N-2)+5}+(N-1))>0,
$$

and $\Phi:=((1-z) R+z N P) /((1-z) R+z \alpha N P)>0$ is the welfare-ratio between group $D$ and $A$. The condition holds if the relative effectiveness of group $D$ is not too strong.

(ii.) For $s_{A}=1$, the utility differential $\Delta_{D}\left(1,0 \mid s_{A}=1\right)=V_{D}(1,1, \theta, \alpha, N)-$ $V_{D}(1,0, \theta, \alpha, N)$ is larger than zero if and only if

$$
\begin{aligned}
& \frac{(1-z) R+z N P}{((1-z) R(1+\theta)+z(1+\alpha \theta) N P))^{2}} \\
- & \frac{(1-z) R(1+(N-1) \theta)+z N P(1-\alpha(1-N) \theta}{\left((1-z) R(1+N \theta+z N P(1+\alpha N \theta))^{2}\right.}>0,
\end{aligned}
$$

which is non-negative if and only if

$$
\theta \leq \theta_{D}^{2}:=\frac{1}{2} \Phi(\sqrt{(N-2) N+5}+(N-1))>0 .
$$

Again, this condition holds if the relative effectiveness of group $D$ is not too strong. Note that $\theta_{D}^{1}>\theta_{D}^{2}$ because $\alpha \geq 2 / N$.

Group $A$ : (iii.) If $s_{D}=0$, the utility differential between $s_{A}=1$ and $s_{A}=0$, $\Delta_{A}\left(1,0 \mid s_{D}=0\right)=V_{A}(1,0, \theta, \alpha, N)-V_{D}(0,0, \theta, \alpha, N)$ is larger than zero if and only if

$$
\begin{gathered}
\frac{\theta N^{3}((1-z) R+z \alpha N P)}{((1-z) R(1+\theta N)+z N P(1+\alpha \theta N))^{2}} \\
-\frac{(1-z) R(N(\alpha+\theta)-1)+z N P(\alpha N(1+\theta)-1))}{((1-z) R(\theta-\alpha)+z N P \alpha(1+\theta))^{2}}
\end{gathered}
$$


which is non-negative if and only if

$$
\theta \geq \theta_{A}^{1}:=\frac{1}{2 N} \Phi(\sqrt{(\alpha N-2) \alpha N+5}-(\alpha N-1))>0 .
$$

This finding and its interpretation are symmetric to case (i.).

(iv.) If $s_{D}=1$, the utility differential between $s_{A}=1$ and $s_{A}=0, \Delta_{A}\left(1,0 \mid s_{D}=\right.$ $1)=V_{A}(1,1, \theta, \alpha, N)-V_{D}(0,1, \theta, \alpha, N)$ is larger than zero if and only if

$$
\begin{gathered}
\frac{\theta((1-z) R+z \alpha N P)}{((1-z) R(1+\theta)+z N P(1+\alpha \theta))^{2}} \\
-\frac{(1-z) R(N \alpha+\theta)-1)+z N P(\alpha(N+\theta)-1)}{((1-z) R(\theta+\alpha N)+z N P(N+\theta))^{2}}
\end{gathered}
$$

which is non-negative if and only if

$$
\theta \geq \theta_{A}^{2}:=\frac{1}{2} \Phi(\sqrt{(\alpha N-2) \alpha N+5}-(\alpha N-1)) .
$$

This finding and its interpretation are symmetric to case (ii.). Note that $\theta_{A}^{2}>\theta_{A}^{1}$.

To summarize, there are four equilibrium configurations:

$$
\begin{array}{lll}
s_{D}=0, s_{A}=0 & \text { if } & \theta_{D}^{1} \leq \theta \leq \theta_{A}^{1} \\
s_{D}=1, s_{A}=0 & \text { if } & \theta \leq \min \left\{\theta_{D}^{1}, \theta_{A}^{2}\right\} \\
s_{D}=0, s_{A}=1 & \text { if } & \theta \geq \max \left\{\theta_{D}^{2}, \theta_{A}^{1}\right\} \\
s_{D}=1, s_{A}=1 & \text { if } & \theta_{A}^{2} \leq \theta \leq \theta_{D}^{2} .
\end{array}
$$

We have already established that $\theta_{D}^{2}<\theta_{D}^{1}$ and $\theta_{A}^{1}<\theta_{A}^{2}$. In addition it is straightforward to show that $\theta_{A}^{2}<\theta_{D}^{2}$ : The difference $\theta_{D}^{2}-\theta_{A}^{2}=(1+a) N-2+$ $\sqrt{(N-2) N+5}-\sqrt{(\alpha N-2) \alpha N+5}$ has to be positive for all $\alpha \geq 2 / N, N \geq 2$, or alternatively $N_{D}+N A-2+\sqrt{\left(N_{D}-2\right) N_{D}+5} \geq \sqrt{\left(N_{A}-2\right) N_{A}+5} \geq 0$. Since the lhs of this inequality is increasing in $N_{D}$, it is sufficient to show that $N_{A}+\sqrt{5}=2+N_{A}-2+\sqrt{(2-2) 2+5} \geq \sqrt{\left(N_{A}-2\right) N_{A}+5}$ is always fulfilled. The rhs of this inequality is always smaller than $\sqrt{N_{A}^{2}+5}$. Squaring both sides and simplifying yields $2 N_{A} \sqrt{5}>0$. Putting $\underline{\theta}=\theta_{A}^{2}$ and $\bar{\theta}=\theta_{D}^{2}$, the claim follows. q.e.d.

\section{A.2: Underdogs and favorites}

For the Tullock contest success function (2) it is straightforward to check from (6) that group $A$ is the underdog [favorite] if and only if the equilibrium winning probability $p_{A}^{*}$ is smaller [larger] than $1 / 2$. It is also straightforward to check that $p_{A}^{a d}$ is equal in sign to $\theta W_{A}\left(s_{A}\right)-W_{D}\left(s_{D}\right)$. We now calculate the values of $p_{a d}^{A}$. 
- Assume that $s_{D}=0, s_{A}=1$ : This is an equilibrium if and only if $\theta \geq \bar{\theta}(\alpha)$. Then $p_{A}^{a d} \geq 0$ if and only if $\theta \geq \Phi(\alpha) / N$ (insert the appropriate rents and solve for $\theta$ ). This function lies below $\Phi(\alpha)$, which in turn lies below $\bar{\theta}(\alpha)$ (cf. Figure $1)$. This property implies that $p_{A}^{a d}(1,0)>0$, effort by group $A$ is a strategic complement to effort by group $D$, and effort by $D$ is a strategic substitute to effort by $A$.

- Assume that $s_{D}=1$ and $s_{A}=0$ which is an equilibrium if and only if $\theta \leq \underline{\theta}(\alpha)$. In that case, $p_{A}^{a d}(0,1) \geq 0$ if and only if $\theta \geq \tilde{\theta}(\alpha):=\alpha N \Phi(\alpha)$. Inspection of $\tilde{\theta}(\alpha)$ shows that this is an increasing function. Comparing $\tilde{\theta}(\alpha)$ and $\underline{\theta}(\alpha)$ at $\alpha=2 / N$ (the smallest value of $\alpha$ to make the problem well defined) reveals that $\tilde{\theta}(2 / N)>\underline{\theta}(2 / N)$. Given that $\underline{\theta}(\alpha)$ is decreasing, the $(\alpha, \theta)$-combinations that are consistent with $s_{D}=1, s_{A}=0$ are always in an area where $p_{A}^{a d}(0,1)<0$ : effort by group $A$ is a strategic substitute to effort by group $D$, and effort by $D$ is a strategic complement to effort by $A$.

- Assume that $s_{D}=s_{A}=1$, which is an equilibrium if and only if $\underline{\theta}(\alpha) \leq$ $\theta \leq \bar{\theta}(\alpha)$. Then, $p_{A}^{a d}(1,1) \geq 0$ iff $\theta \geq \Phi(\alpha)$. This type of equilibrium does dot depend on the sign of the cross derivative. However, it has to be relatively small in absolute terms.

\section{Appendix B: Proofs for Section 4}

\section{B.2: Proof of Proposition 2}

1. If $\theta \leq \underline{\theta}$ the equilibrium is $\{0,1\}$, and we compare utility levels $V_{D}(0,0), V_{D}(0,1)$ and $V_{A}(0,0), V_{A}(0,1)$. Members of group $A$ are better off by revealed preference. Individuals of group $D$ are worse off, $V_{D}(0,1)-V_{D}(0,0)<0$, iff

$$
-\frac{(N-1) \theta\left(1+N+N(1+N) \theta(N-1) N \theta^{2}\right)}{(1+\theta)^{2}(1+N \theta)^{2}((1-z) R+z N P)}<0,
$$

which is always fulfilled.

2. If $\theta \in[\underline{\theta}, \bar{\theta}]$ the equilibrium is $\{1,1\}$, and we compare utility levels $V_{D}(0,0)$, $V_{D}(1,1)$ and $V_{A}(0,0), V_{A}(1,1)$. Members of group $A$ are worse off, $V_{A}(1,1)<$ $V_{A}(0,0)$, iff

$$
-\frac{(N-1)}{(1+\theta)^{2}((1-z) R+z N P)}<0
$$


and members of group $D$ are worse off, $V_{D}(1,1)<V_{D}(0,0)$, iff

$$
-\frac{(N-1) \theta}{(1+\theta)^{2}((1-z) R+z N P)}<0
$$

Both conditions are always fulfilled.

3. The proof of this case is symmetric to the proof of case 1 .

q.e.d.

\section{B.2: Proof of Propositions 3}

Proposition 3.a: As the equilibrium is $\left(s_{A}, s_{D}\right)=(1,1)$, we compare utilities $V_{A}(1,1), V_{A}(0,0)$, and $V_{D}(1,1), V_{D}(0,0)$, respectively. Our aim is to arrive at conditions on the model parameters $(\theta, \alpha, N)$ such that members in both groups are better off with an IGEIS rather than without it. ${ }^{9}$

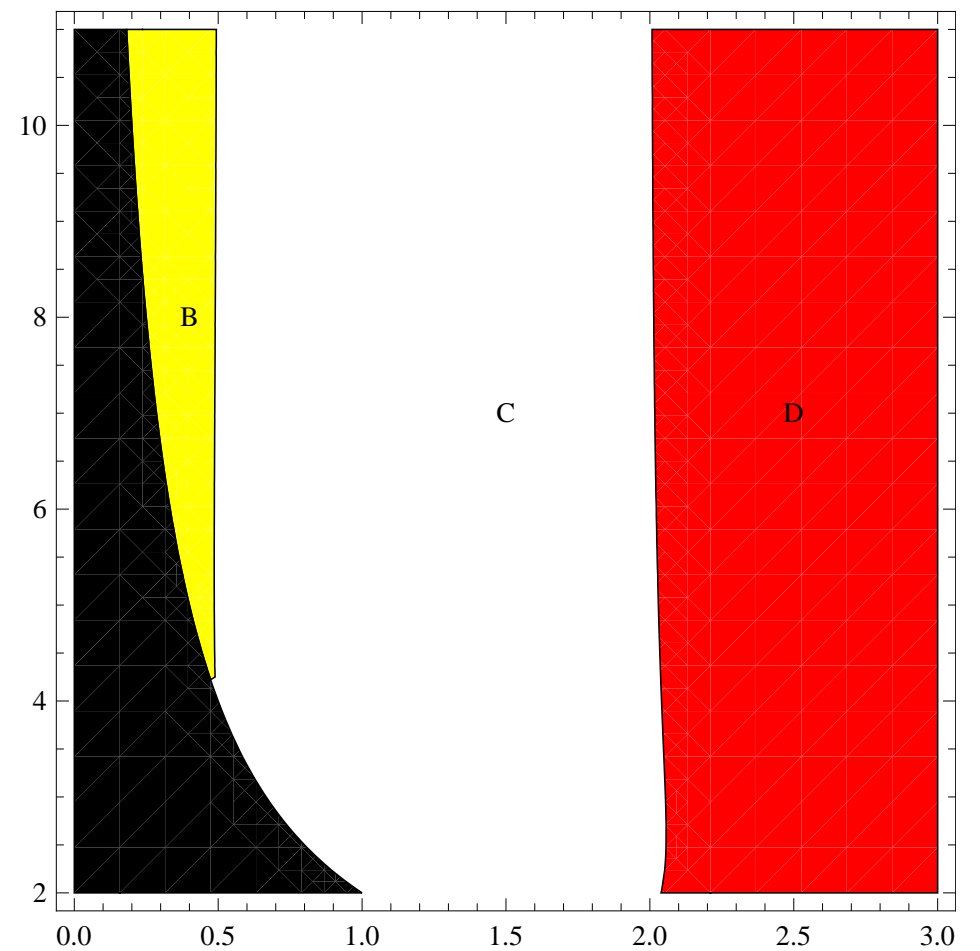

Figure 3: $\alpha$ - $N$-combinations for which $V_{A}(1,1)-V_{A}(0,0)$ or $V_{D}(1,1)-V_{D}(0,0)$ are positive. $\alpha \in[0,3]$ is on the abscissa and $N \in[2,11]$ is on the ordinate.

\footnotetext{
${ }^{9}$ The proof of the proposition has been carried out by the help of Mathematica 7.0. A file with the detailed programming code can be received from the authors upon request.
} 
As a first set of conditions, we must ensure that both groups have at least two members and that $\left(s_{A}, s_{D}\right)=(1,1)$ is in fact a Nash equilibrium. This requires that:

- $\alpha \geq 2 / N$,

- $\underline{\theta} \leq \theta \leq \bar{\theta}$.

Next, group members in $A$ must better off with $\left(s_{A}, s_{D}\right)=(1,1)$. Checking $V_{A}(1,1)>V_{A}(0,0)$ yields that

- $\theta>\theta_{A}:=\frac{\sqrt{(\alpha-1)^{2} N\left((\alpha-1)^{2} N+4\right)}-(2+((\alpha-2) \alpha-1) N)}{1+(\alpha-2) N}$,

- $(1+\alpha N)>2 N$.

Analogously, individuals of group $D$ are better off iff $V_{D}(1,1)>V_{D}(0,0)$ which requires that

- $\theta<\theta_{D}:=\frac{\sqrt{(\alpha-1)^{2} N\left(4 \alpha+(\alpha-1)^{2} N\right)}-((\alpha(2+\alpha)-1) N-2 \alpha)}{\alpha(N-1)}$,

- $(1+N)>2 \alpha N$.

While the set of $(\alpha, N)$-combinations consistent with all six inequalities just presented is not empty, it cannot be characterized analytically in an explicit form. Yet, a graphical illustration is feasible. Figure 3 provides one. Area $A$ violates $\alpha \geq 2 / N$. Area $B$ is the set of all pairs $(\alpha, N)$ such that $V_{D}(1,1)-V_{D}(0,0)>0$. In all other cases (areas $C$ and $D), V_{D}(1,1)-V_{D}(0,0)<0$. Area $D$ is the range where $V_{A}(1,1)-V_{A}(0,0)>0$. In all other cases (areas $B$ and $\left.C\right), V_{A}(1,1)-V_{A}(0,0)<0$. q.e.d.

Proposition 3.b: Suppose that $\theta<\underline{\theta}$ (the case $\theta>\bar{\theta}$ follows by a similar token). We compare $s_{D}=s_{A}=0$ and $s_{D}=1, s_{A}=0$. By a revealed-preference argument, group $D$ must be better off because group $A$ 's choice is the same in both situations. Denote by $R_{A}=(1-z) R+z \alpha N P$ and $R_{D}=(1-z) R+z N P$ the aggregate group rents. Group $A$ is better off, $V_{A}(1,0)>V_{A}(0,0)$, iff

$$
\frac{\Psi_{1}}{\Psi_{2}}\left(\frac{1}{\alpha} R_{A}\left((N-1) N \theta^{2} R_{A}+N \theta(\alpha N+1) R_{D}\right)+(N+1) R_{D}\right)<0,
$$

where $\Psi_{1}=\theta(\alpha N-1) R_{D}^{2} R_{A}$ and $\Psi_{2}=N^{2}(1+\theta)^{2} R_{A}^{2}\left(R_{D}+N \theta R_{A}\right)$. This condition, however, can never be fulfilled given the assumptions of the model. q.e.d. 


\section{References}

- Akerlof, G.A., R.E. Kranton (2005), Identity and the economics of organizations, Journal of Economic Perspectives 19, 9-32.

- Baik, K.H. (2008), Contests with group-specific public goods prizes, Social Choice and Welfare 30, 103-117.

- Baik, K.H., S. Lee (2001), Strategic groups and rent dissipation, Economic Inquiry 39, 672-684.

- Baik, K.H., J.F. Shogren (1992): Strategic Behavior in Contests: Comment, American Economic Review 82, 359-362.

- Bloch, F., S. Sánchez-Pagś, R. Soubeyran (2006): When does universal peace prevail? Secession and group formation in conflict, Economics of Governance 7, 3-29.

- Dixit, A. (1987): Strategic Behaviour in Contests, The American Economic Review 77, 89198.

- Esteban, J., D. Rey (2001): Free Riding and the Group Size Paradox, American Political Science Review, 95, 663-672.

- Grossman, H. (2001): The Creation of Effective Property Rights. American Economic Review 91, 347-352.

- Hirshleifer, J. (1991): The Paradox of Power. Economics and Politics 3, 177200.

- Katz, E., S. Nitzan, J. Rosenberg (1990): Rent-Seeking for Pure Public Goods, Public Choice 65, 49-60.

- Konrad, K. (2009): Strategy and Dynamics in Contests, Oxford: Oxford University Press.

- Leininger, W. (1993): More Efficient Rent-Seeking - A Mnchhausen Solution, Public Choice 75, 43-62.

- Nitzan, S. (1991a): Collective rent dissipation, Economic Journal 101, 15221534. 
- Nitzan, S. (1991b): Rent-Seeking with Non-Identical Sharing Rules, Public Choice 71, 43-50.

- Nitzan, S. (1994): More on more efficient rent seeking and strategic behavior in contests: Comment, Public Choice 79, 355-356.

- Nitzan, S., K. Ueda (2009): Collective Contests for Commons and Club Goods, Journal of Public Economics 93, 48-55.

- Noh, S.J. (2002): Resource distribution and stable alliance with endogenous sharing rule, European Journal of Political Economy 18, 129-151.

- Olson, M. (1965): The Logic of Collective Action. Cambridge, MA: Harvard University Press.

- Pecorino, P., A. Temimi (2008): The Group Size Paradox Revisited, Journal of Public Economic Theory 10, 785-799. 


\section{CESifo Working Paper Series}

for full list see www.cesifo-group.org/wp

(address: Poschingerstr. 5, 81679 Munich, Germany, office@cesifo.de)

3093 Huw David Dixon, A Unified Framework for Using Micro-Data to Compare Dynamic Wage and Price Setting Models, June 2010

3094 Helmuth Cremer, Firouz Gahvari and Pierre Pestieau, Accidental Bequests: A Curse for the Rich and a Boon for the Poor, June 2010

3095 Frank Lichtenberg, The Contribution of Pharmaceutical Innovation to Longevity Growth in Germany and France, June 2010

3096 Simon P. Anderson, Øystein Foros and Hans Jarle Kind, Hotelling Competition with Multi-Purchasing: Time Magazine, Newsweek, or both?, June 2010

3097 Assar Lindbeck and Mats Persson, A Continuous Theory of Income Insurance, June 2010

3098 Thomas Moutos and Christos Tsitsikas, Whither Public Interest: The Case of Greece's Public Finance, June 2010

3099 Thomas Eichner and Thorsten Upmann, Labor Markets and Capital Tax Competition, June 2010

3100 Massimo Bordignon and Santino Piazza, Who do you Blame in Local Finance? An Analysis of Municipal Financing in Italy, June 2010

3101 Kyriakos C. Neanidis, Financial Dollarization and European Union Membership, June 2010

3102 Maela Giofré, Investor Protection and Foreign Stakeholders, June 2010

3103 Andrea F. Presbitero and Alberto Zazzaro, Competition and Relationship Lending: Friends or Foes?, June 2010

3104 Dan Anderberg and Yu Zhu, The Effect of Education on Martial Status and Partner Characteristics: Evidence from the UK, June 2010

3105 Hendrik Jürges, Eberhard Kruk and Steffen Reinhold, The Effect of Compulsory Schooling on Health - Evidence from Biomarkers, June 2010

3106 Alessandro Gambini and Alberto Zazzaro, Long-Lasting Bank Relationships and Growth of Firms, June 2010

3107 Jenny E. Ligthart and Gerard C. van der Meijden, Coordinated Tax-Tariff Reforms, Informality, and Welfare Distribution, June 2010 
3108 Vilen Lipatov and Alfons Weichenrieder, Optimal Income Taxation with Tax Competition, June 2010

3109 Malte Mosel, Competition, Imitation, and R\&D Productivity in a Growth Model with Sector-Specific Patent Protection, June 2010

3110 Balázs Égert, Catching-up and Inflation in Europe: Balassa-Samuelson, Engel's Law and other Culprits, June 2010

3111 Johannes Metzler and Ludger Woessmann, The Impact of Teacher Subject Knowledge on Student Achievement: Evidence from Within-Teacher Within-Student Variation, June 2010

3112 Leif Danziger, Uniform and Nonuniform Staggering of Wage Contracts, July 2010

3113 Wolfgang Buchholz and Wolfgang Peters, Equity as a Prerequisite for Stable Cooperation in a Public-Good Economy - The Core Revisited, July 2010

3114 Panu Poutvaara and Olli Ropponen, School Shootings and Student Performance, July 2010

3115 John Beirne, Guglielmo Maria Caporale and Nicola Spagnolo, Liquidity Risk, Credit Risk and the Overnight Interest Rate Spread: A Stochastic Volatility Modelling Approach, July 2010

3116 M. Hashem Pesaran, Predictability of Asset Returns and the Efficient Market Hypothesis, July 2010

3117 Dorothee Crayen, Christa Hainz and Christiane Ströh de Martínez, Remittances, Banking Status and the Usage of Insurance Schemes, July 2010

3118 Eric O'N. Fisher, Heckscher-Ohlin Theory when Countries have Different Technologies, July 2010

3119 Huw Dixon and Hervé Le Bihan, Generalized Taylor and Generalized Calvo Price and Wage-Setting: Micro Evidence with Macro Implications, July 2010

3120 Laszlo Goerke and Markus Pannenberg, 'Take it or Go to Court' - The Impact of Sec. 1a of the German Protection against Dismissal Act on Severance Payments -, July 2010

3121 Robert S. Chirinko and Daniel J. Wilson, Can Lower Tax Rates be Bought? Business Rent-Seeking and Tax Competition among U.S. States, July 2010

3122 Douglas Gollin and Christian Zimmermann, Global Climate Change and the Resurgence of Tropical Disease: An Economic Approach, July 2010

3123 Francesco Daveri and Maria Laura Parisi, Experience, Innovation and Productivity Empirical Evidence from Italy's Slowdown, July 2010 
3124 Carlo V. Fiorio and Massimo Florio, A Fair Price for Energy? Ownership versus Market Opening in the EU15, July 2010

3125 Frederick van der Ploeg, Natural Resources: Curse or Blessing?, July 2010

3126 Kaisa Kotakorpi and Panu Poutvaara, Pay for Politicians and Candidate Selection: An Empirical Analysis, July 2010

3127 Jun-ichi Itaya, Makoto Okamura and Chikara Yamaguchi, Partial Tax Coordination in a Repeated Game Setting, July 2010

3128 Volker Meier and Helmut Rainer, On the Optimality of Joint Taxation for NonCooperative Couples, July 2010

3129 Ryan Oprea, Keith Henwood and Daniel Friedman, Separating the Hawks from the Doves: Evidence from Continuous Time Laboratory Games, July 2010

3130 Mari Rege and Ingeborg F. Solli, The Impact of Paternity Leave on Long-term Father Involvement, July 2010

3131 Olaf Posch, Risk Premia in General Equilibrium, July 2010

3132 John Komlos and Marek Brabec, The Trend of BMI Values by Centiles of US Adults, Birth Cohorts 1882-1986, July 2010

3133 Emin Karagözoğlu and Arno Riedl, Information, Uncertainty, and Subjective Entitlements in Bargaining, July 2010

3134 John Boyd, Gianni De Nicolò and Elena Loukoianova, Banking Crises and Crisis Dating: Theory and Evidence, July 2010

3135 Michael R. Baye, Dan Kovenock and Casper G. de Vries, The Herodotus Paradox, July 2010

3136 Martin Kolmar and Hendrik Rommeswinkel, Group Contests with Complementarities in Efforts, July 2010

3137 Carolina Manzano and Xavier Vives, Public and Private Learning from Prices, Strategic Substitutability and Complementarity, and Equilibrium Multiplicity, July 2010

3138 Axel Löffler, Gunther Schnabl and Franziska Schobert, Inflation Targeting by Debtor Central Banks in Emerging Market Economies, July 2010

$3139 \mathrm{Yu}-\mathrm{Fu}$ Chen and Michael Funke, Global Warming and Extreme Events: Rethinking the Timing and Intensity of Environmental Policy, July 2010

3140 Lawrence M. Kahn, Labor Market Policy: A Comparative View on the Costs and Benefits of Labor Market Flexibility, July 2010 
3141 Ben J. Heijdra, Jochen O. Mierau and Laurie S.M. Reijnders, The Tragedy of Annuitization, July 2010

3142 Erkki Koskela, Outsourcing Cost and Tax Progression under Nash Wage Bargaining with Flexible Outsourcing, July 2010

3143 Daniel Osberghaus and Christiane Reif, Total Costs and Budgetary Effects of Adaptation to Climate Change: An Assessment for the European Union, August 2010

3144 Philip E. Graves, Benefit-Cost Analysis of Environmental Projects: A Plethora of Systematic Biases, August 2010

3145 Sabrina Di Addario and Daniela Vuri, Entrepreneurship and Market Size. The Case of Young College Graduates in Italy, August 2010

3146 Shoshana Amyra Grossbard and Alfredo Marvăo Pereira, Will Women Save more than Men? A Theoretical Model of Savings and Marriage, August 2010

3147 Jarko Fidrmuc, Time-Varying Exchange Rate Basket in China from 2005 to 2009, August 2010

3148 Ilja Neustadt and Peter Zweifel, Is the Welfare State Sustainable? Experimental Evidence on Citizens' Preferences for Redistribution, August 2010

3149 Marcus Dittrich and Andreas Knabe, Wage and Employment Effects of Non-Binding Minimum Wages, August 2010

3150 Shutao Cao, Enchuan Shao and Pedro Silos, Fixed-Term and Permanent Employment Contracts: Theory and Evidence, August 2010

3151 Ludger Woessmann, Cross-Country Evidence on Teacher Performance Pay, August 2010

3152 Lorenzo C. G. Pozzi, Casper G. de Vries and Jorn Zenhorst, World Equity Premium Based Risk Aversion Estimates, August 2010

3153 Volker Grossmann, Thomas M. Steger and Timo Trimborn, Dynamically Optimal R\&D Subsidization, August 2010

3154 Alexander Haupt, Tim Krieger and Thomas Lange, A Note on Brain Gain and Brain Drain: Permanent Migration and Education Policy, August 2010

3155 António Afonso and Christophe Rault, Long-run Determinants of Sovereign Yields, August 2010

3156 Franziska Tausch, Jan Potters and Arno Riedl, Preferences for Redistribution and Pensions. What can we Learn from Experiments?, August 2010

3157 Martin Kolmar and Andreas Wagener, Inefficient Group Organization as Optimal Adaption to Dominant Environments, August 2010 